\title{
Mechanical Support for Straw Tubes
}

\author{
Hans Jöstlein \\ Fermi National Accelerator Laboratory \\ P.O. Box 500 \\ Batavia, Illinois 60510
}

March 11, 1990 


\section{Mechanical Support for Straw Tubes}

\section{Abstract}

A design is proposed for mounting a large number of straw tubes to form an SSC central tracking chamber. The assembly is precise and of very low mass. The fabrication is modular and can be carried out with a minimum of tooling and instrumentation. Testing of modules is possible prior to the final assembly.

\section{Introduction}

Central tracking devices for detectors at the Superconducting Super Collider (SSC) must cope with far more demanding conditions than existing collider detectors.

The crossing time is only $15 \mathrm{nsec}$, the luminosity is $10^{33} \mathrm{per} \mathrm{cm}^{2}$ and second, with multiple events per crossing quite common, and each event multiplicity will average in excess of 100 tracks.

One tracker discussed in the past for this application consists of many small diameter ( 3 to $4 \mathrm{~mm}$ ) drift tubes, closely packed for high redundancy, short drift time and a large number of elements.

The tubes will be made like soda straws from aluminized mylar strip. A wire is stretched down the middle as in conventional drift tubes.

\section{Mechanical Requirements}

We are addressing here the question how to fabricate a tracker containing tens of thousands of such tubes, all positioned with adequate accuracy (typically $0.1 \mathrm{~mm}$ desirable, $0.2 \mathrm{~mm}$ acceptable), supporting the wire tension (about $50 \mathrm{~g} /$ tube) and presenting a minimum amount of multiple scattering material (10\% of a radiation length or less is desirable).

The assembly must also provide for adequate gas flow (mainly to dissipate heat from discharges in the tubes due to ionizing radiation), gas tightness, high voltage connection and signal extraction/ pre amplification.

The last two points are typically addressed through rather complicated end plug assemblies, which are not discussed in this note. 


\section{Description of the Structure}

Typical central trackers consist of a cylindrical assembly with many concentric tracker planes, often grouped in super layers. Figure 1 shows such a structure.

Throughout this note I have made choices for dimensions in order to get a concrete feeling for the solution. All thesenumbers are, of course, subject to change, adaptation and optimization. It will be easy for the reader to scale the solution presented here to his own requirement.

\section{Modularity}

The first thing one can notice in Fig. 1 is that the cylindrical tracker is made up of 24 segment modules of $15^{\circ}$ angular coverage.

A device as complex as the central tracker is built much more easily from modules, which can be developed and produced in a small laboratory, and tested individually prior to assembly.

The modules look like long lightweight boxes. They are positioned by locating with pins on a pair of NC machined end rings, which might be $0.5 \mathrm{~cm}$ thick. The modules themselves force the end rings to stay in a plane.

\section{Dimensions and Parameters}

Table I shows the set of dimensions chosen. The tracker is $3 \mathrm{~m}$ long, and has an outer diameter of $1.6 \mathrm{~m}$. One of the modules is shown in Fig. 2 . One can see the four superlayers of straws. The rest of the space is empty.

\section{Module Design}

The key to the module design are the webs, shown in Fig. 3, which provide accurate location for the straws. 
The webs are evenly spaced (about $0.3 \mathrm{~m}$ apart) along the module. They are made from $0.25 \mathrm{~mm}$ thick carbon fiber composite. The guide holes for the straws are laser drilled to about $0.1 \mathrm{~mm}$ accuracy, with a diameter about $0.1 \mathrm{~mm}$ larger than the straw O.D. Between holes there is a $0.25 \mathrm{~mm}$ bridge. It is quite possible to accommodate small angle stereo layers in those webs; since the holes are CNC laser milled anyway, one needs only different software for each web to allow for the slant angles.

These webs serve also to provide the structural skeleton for the module, once they are bonded to an outer skin, made from similar material. The resultant structure is like an insect's outer skeleton, providing bend-, torsional- and compressional stiffness. The latter is needed to carry the wire tension resultant force.

\section{Assembly Sequence}

To assemble a module, one begins by placing the webs, edge-held by suitable holders, on a granite block, lined up against a straight edge (see Fig. 4). This setup guarantees the final straightness of the module.

With end plate in place (not shown), one begins pulling straws from a magazine (in line with the granite table) through the first end plate and through successive webs until the straws abut a stop (perhaps in the form of a stepped hole) at the second end plate. It may seem difficult to pull the straws this way, but one must remember that the web structure is wide open and the the straws are being pulled in a straight line, with very little chance of being kinked. Much time will be saved by obviating the need to measure placement of every tube; the webs guarantee accurate placement.

When a layer (or pair of layers) is completely inserted, one will use a very small amount of glue (needle dispensed) to anchor the straws to the webs. This stabilizes the webs in the longitudinal direction. 
Hans Jöstlein $\quad$ Page $4 \quad 3 / 11 / 90$

\section{Gas Flow}

The straw ends present a crowded and difficult area. One must make contact with the straw grounds, hold the wire reliably with high tension, insulate the high voltage, and channel the gas. In the present design, the gas connections are made somewhat easier. Rather than trying to gas seal each straw, one can make the outer box gas tight, and allow the space between the straws to be filled with clean chamber gas. Each straw will have a small hole through the wall near the end where the insulating sleeve from the end plug assembly shields the wire from electric breakdown due to sharp edges.

The space between the end plate and the last web serves as a gas plenum for supply on one end, and return on the other. Almost all the gas is channeled through the straws, because the webs impede flow in the outer space. Some flow, though, occurs there through the annular spaces around each straw, keeping the gas well purged.

\section{Completion of a Module}

When all the straws have been threaded and glued to the webs, one will glue the outer box panels against the webs and the end plates. These glue joints must be very strong and reliable. One will consider using small Lmoldings or slotted stock for that purpose. More work needs to be done here.

The resulting module is light (14 kg) and quite strong, and can be easily handled by the end plates.

Wires can be strung in a variety of ways from the ends. This operation is independent of the features described here, and can be performed away from the granite table. 
Straw Tube -Straw Man Design

Hans Jostlein

Input Constants

$\mathrm{Pi}$

Module Thickness

Width

Length

Web thickness

Web(and outer skin) density

Web(and outer skin) rad. length

Web spacing

Outer skin thickness

End Plate Thickness

End Plate density(Al)

Layers/super layer

\# super layers

Straw $\varnothing$

Straw gap within layers

Straw wall thickness

Staw wall density

Staw wall radiation length

Wire $\varnothing$

Wire density

Wire rad. length

Gas density

Gas rad. length

Derived Quantities

Module Area

\# of Straws/module

Weight of one straw

Weight of Straws per module

Weight of Wire per module

Weight of box /mod. (less end plate

Weight of webs per module

Weight of 2 end plates

weight of gas/module

Module weight complete
3.14159265

$0.3 \mathrm{~m}$

$0.15 \mathrm{~m}$

$3 \mathrm{~m}$

$0.00025 \mathrm{~m}$

$1500 \mathrm{~kg} / \mathrm{m}^{\wedge} 3$

$400 \mathrm{~kg} / \mathrm{m}^{\wedge} 2$

$0.3 \mathrm{~m}$

$0.00025 \mathrm{~m}$

$0.0124 \mathrm{~m}$

$8900 \mathrm{~kg} / \mathrm{m}^{\wedge} 2$

. 10

4

$0.003 \mathrm{~m}$

$0.00025 \mathrm{~m}$

$0.000025 \mathrm{~m}$

$1390 \mathrm{~kg} / \mathrm{m}^{\wedge} 3$

$399.5 \mathrm{~kg} / \mathrm{m}^{\wedge} 2$

$0.00005 \mathrm{~m}$

$19300 \mathrm{~kg} / \mathrm{m}^{\wedge} 3$

$67.6 \mathrm{~kg} / \mathrm{m}^{\wedge} 2$

$1.8 \mathrm{~kg} / \mathrm{m}^{\wedge} 3$

$450.00 \mathrm{~kg} / \mathrm{m}^{\wedge} 2$

Mass and Radiation Lengths

Gas

Straw Tubes

$0.45 \mathrm{~m}^{\wedge} 2$

1846

$0.00098253 \mathrm{~kg}$

$1.814 \mathrm{~kg}$

$0.210 \mathrm{~kg}$

$1.013 \mathrm{~kg}$

$0.186 \mathrm{~kg}$

$9.932 \mathrm{~kg}$

$0.243 \mathrm{~kg}$

$13.397 \mathrm{~kg}$

Wire

Box (less end plates)

Webs

Total per module

$\mathrm{kg} / \mathrm{m}^{\wedge} \mathbf{2}$

0.540

4.031

0.466

2.250

0.4125

7.6998
L/Lrad

0.0012

0.0101

0.0069

0.0056

0.0010

0.0248

TABLE I 


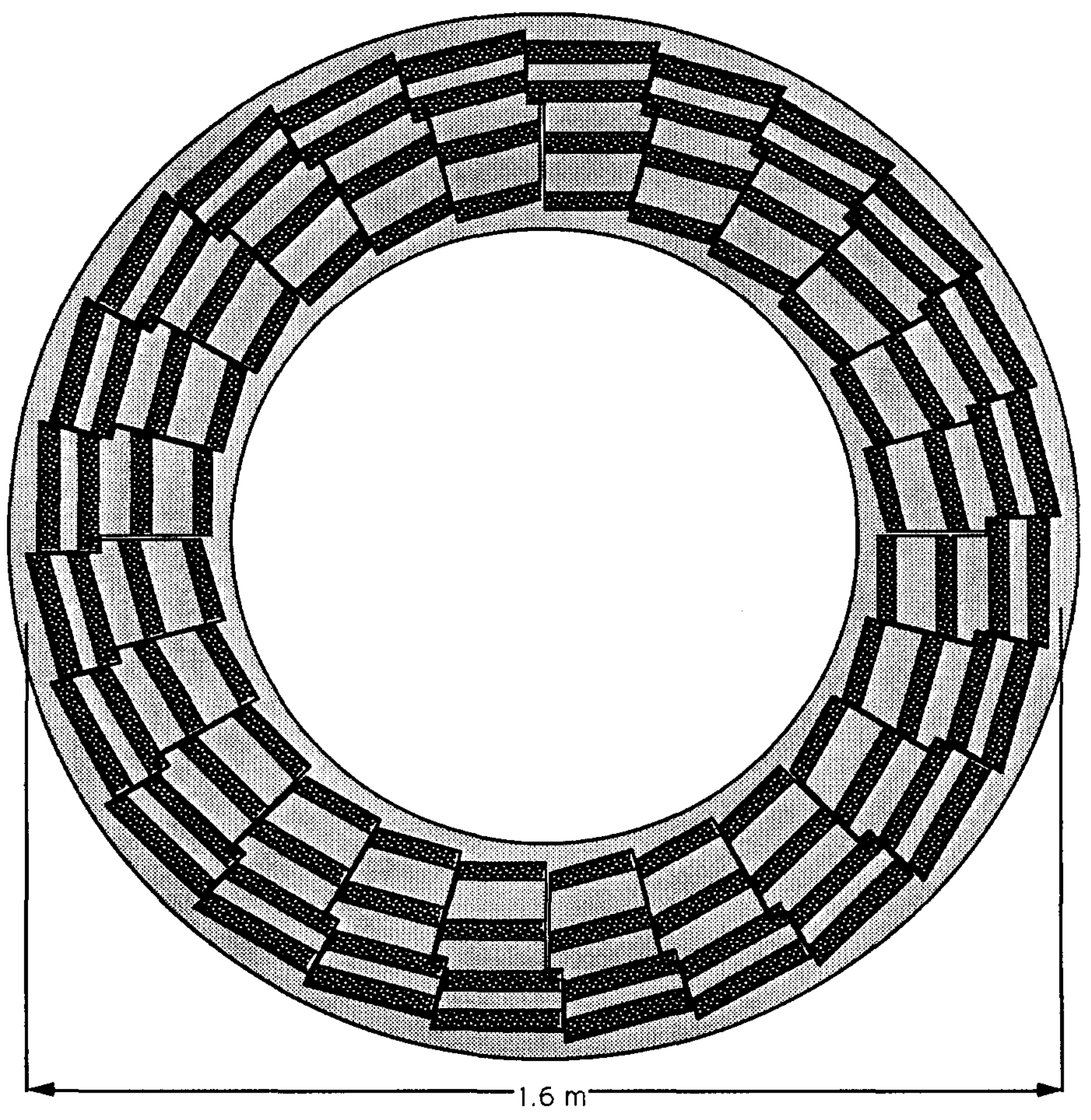

Fig. 1 Modules mounted on End Rings to form a complete Cylinder

Hans Jöstlein 3/101990 


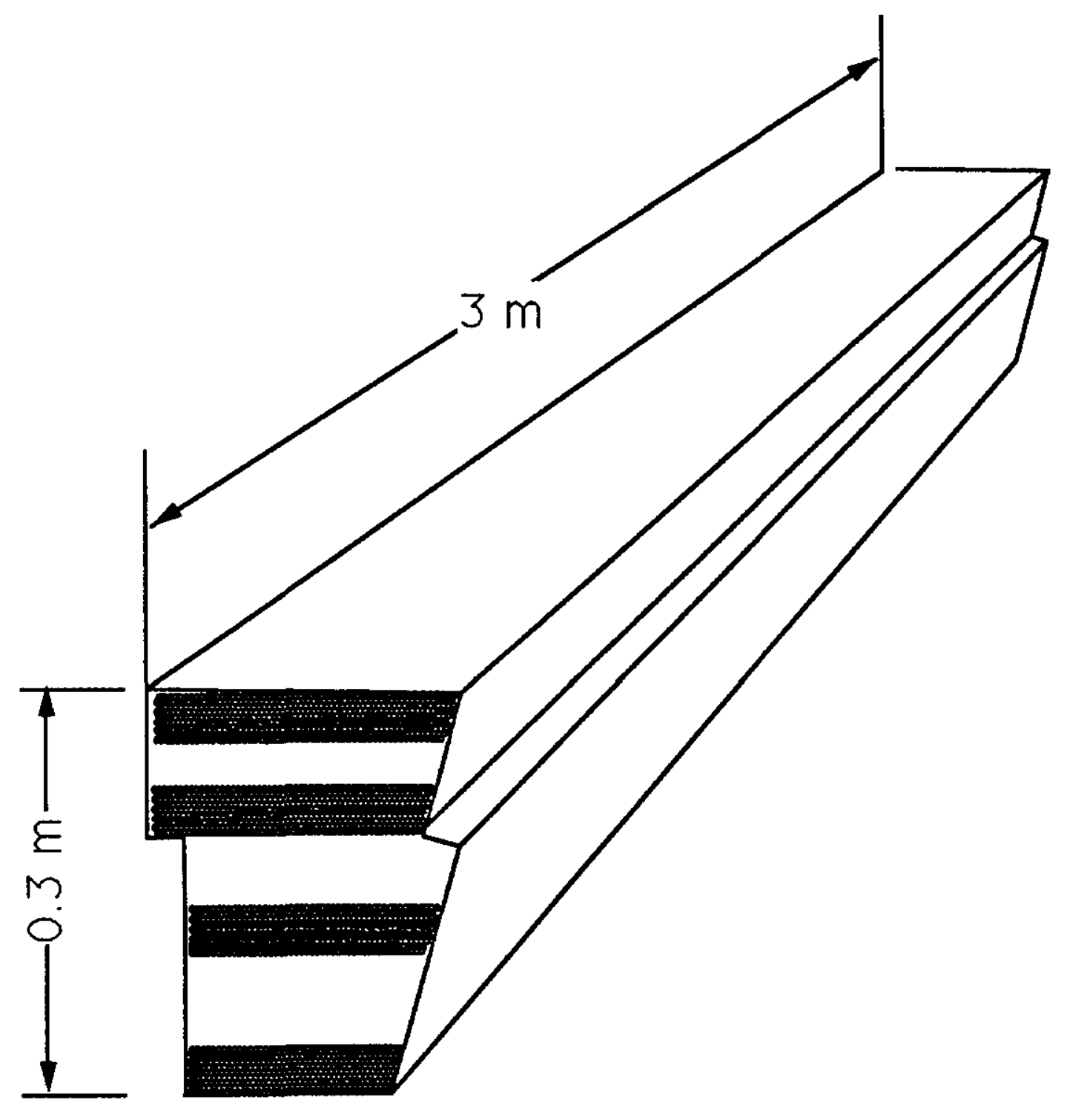

Fig. 2 One of the Modules

Hans Jöstle in

$3 / 10 / 1990$ 




Fig. 3 One of the Locator Webs

Hans Jöstle in $3 / 10 / 1990$ 


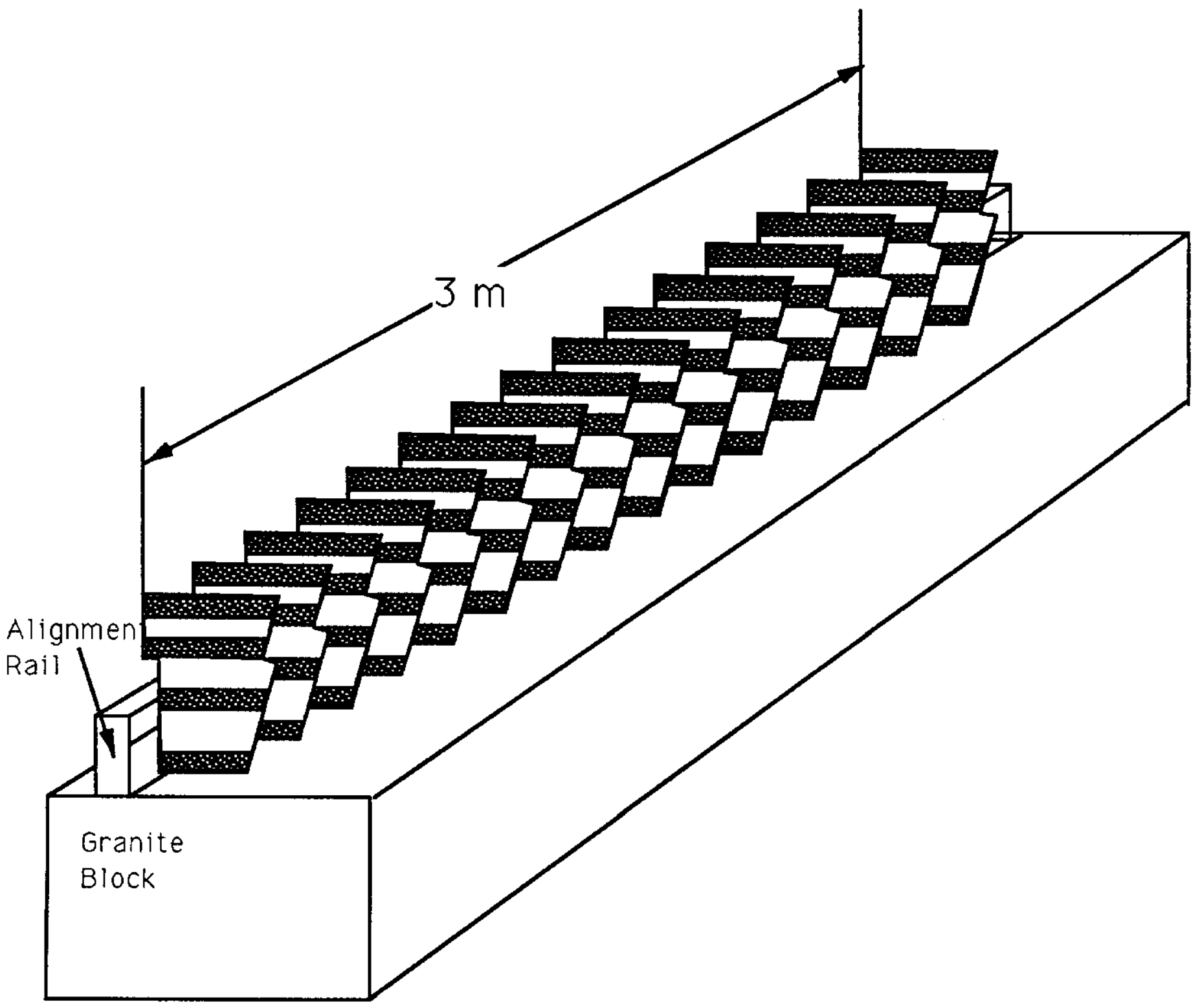

Fig. 4 Assembly of Locator Webs on Granite Table

Hans Jöstlein $3 / 101990$ 